\title{
Prevalence of congenital colour vision deficiency among Black school children in Durban, South Africa
}

\author{
Khathutshelo Percy Mashige* ${ }^{*}$ and Diane Beverly van Staden 1
}

\begin{abstract}
Objectives: Congenital colour vision deficiency (CCVD) is an x-linked chromosome disorder that results from abnormalities in one or all three-cone type's photoreceptors. Early assessment and diagnosis of CCVD is necessary to minimise the disability associated with the condition. Multistage sampling was used to determine the prevalence of CCVD among Black South African school children in Durban, South Africa. The examination included visual acuity measurements, ocular motility evaluation, retinoscopy, auto-refraction, and examination of the anterior segment, media and fundus. Colour vision testing was performed using Colour Vision Testing Made Easy colour plates (Home Vision Care, Gulf Breeze, FL).

Results: 1305 (704 boys and 601 girls) Black school children participated in the study. The overall prevalence of colour vision deficiency was $29(2.2 \%)$, which was higher in boys $(25,4.2 \%)$ than girls $(4,0.6 \%)$, with prevalence of protanopia and deuteranopia found to be $10(0.7 \%)$ and $19(1.5 \%)$, respectively. The prevalence of protanopia and deuteranopia among males was nine (1.5\%) and 16 (2.7\%) respectively, which was significantly higher than the 1 $(0.1 \%)$ protanopia and $3(0.4 \%)$ deuteranopia in females $(p<0.05)$. Policies and guidelines for comprehensive school eye health programmes which screen children for CCVD are required in South Africa.
\end{abstract}

Keywords: Colour vision deficiency, Red-green defects, Prevalence, School children, South Africa

\section{Introduction}

Colour vision deficiency is a common disorder of vision that results in the inability to see certain colours or perceive their differences [1]. The prevalence of colour vision deficiency is expected to increase globally with the growing population, and varies among different races and geographical areas [2-4]. It has been reported that most people with colour vision defects remain undiagnosed [3, 4]. Colour vision deficiency is therefore under-reported due to a lack of its awareness and the absence of proper screening to detect this in the general population $[4,5]$. Colour vision deficiency can be classified as congenital or acquired, with the former being a non-progressive, untreatable disorder that is constant throughout life $[6$,

\footnotetext{
*Correspondence: mashigek@ukzn.ac.za

Discipline of Optometry, School of Health Sciences, University

of KwaZulu-Natal, Private Bag X54001, Durban 4000, South Africa
}

7]. Acquired colour vision defects are secondary to ocular or general pathology, such as neurological disease, some metabolic disorders, drug toxicity and prolonged exposure to certain solvents and medications [5].

Persons with normal colour vision have three types of retinal cone photoreceptors that aid in perceiving red, green and blue colours [4]. Those with abnormal cones will perceive colours differently [4]. There are various types of colour vision deficiency namely monochromacy, dichromacy and trichromacy [4]. Monochromacy is complete colour blindness, this rare condition occurring when two or three of the cone pigments are missing [4, 8]. Dichromacy occurs when a person only has two retinal cones types that are able to perceive colour, resulting in the total absence of one colour. "Dichromacy includes protanopia (caused by the complete absence of red retinal photoreceptors), deuteranopia (caused by the absence of green retinal 
photoreceptors) and tritanopia (complete absence of blue retinal receptors) [8]". "In anomalous trichromacy, one of the three cone pigments is altered in its spectral sensitivity and includes protanomaly (involves reduced sensitivity to red), deuteranomaly (involves reduced sensitivity to green) and tritanomaly in which the spectral sensitivity of the red, green and blue/yellow receptors is altered [8]".

Although statistics vary across different groups and populations, the prevalence of CCVD in European Caucasians is approximately $8 \%$ in men and $0.4 \%$ in women, with between 4 and $6.5 \%$ prevalence in men of Chinese and Japanese ethnicity [9]. The prevalence of CCVD has also been reported to be rising in men of African ethnicity [9]. Although CCVD is incurable and does not cause complete blindness [10], those with the defect (except a few mildly affected deuteranomals) have reported problems in everyday life and at work [5, 11]. For instance, occupations where CCVD is a disadvantage include art teaching, interior design, histopathology, horticulture, geology, diamond grading and metallurgy [12]. Persons with CCVD should, therefore, ideally know about their condition so that they can be advised on appropriate career choices, especially during their early education years. However, Cole [13] reported that many school children are unaware of their colour vision status, which could negatively impact on their school performance. Moreover, early diagnosis of CCVD in children is vital for teachers to make necessary adjustments to the teaching methods for effective and appropriate learning [14]. There is a paucity of published research in South Africa about the prevalence of CCVD among school children. The aim of this study was to determine the prevalence of CCVD Black school children in Durban, South Africa.

\section{Main text}

\section{Methods and materials}

\section{Study area and sampling}

The participants were recruited from geographically contagious areas of Durban consisting of urban, peri-urban and rural areas. These areas included the South, Inner West Region, and Outer West Regions of the Durban metropolitan area (Additional file 1).

Two field workers assisted in recruiting study participants, with those who agreed to participate in the study being transported by one field worker to the examination site (University of KwaZulu-Natal Optometry Clinic), while the other fieldworker moved to the next selected site. During the field work, the head of the household was informed of the nature and details of the study, the date of the clinical examination as well as transportation arrangements for their children.

\section{Sampling procedure and sample size}

The study participants were selected from the three regions of the Durban area through multistage sampling technique. Simple random sampling was then used to select eight areas from the 14 urban, and eight from the 15 peri-urban/rural areas. Finally, systematic random sampling was used to select study participants. The minimum sample size for the study was calculated by using the formula for estimating a single population proportion [15]:

$$
\mathrm{N}=\mathrm{Z}^{2} \times(\mathrm{P}) \times(1-\mathrm{P}) / \mathrm{C}^{2}
$$

where $\mathrm{N}=$ minimum required sample size, $\mathrm{Z}=$ value of $\mathrm{z}$ statistic at $95 \%$ confidence level $=1.96, \mathrm{P}=$ assumed prevalence of congenital colour vision defects $=8 \%$ for maximum sample size, $\mathrm{C}=$ maximum acceptable sampling error $=1.6 \%$.

$$
(1.96)^{2} \times(0.08) \times(1-0.08) /(0.016)^{2}=1105
$$

An additional 200 participants were added to compensate for non-response, missing data, sub-group analysis, and to enhance generalisation of findings through a larger sample size, which gave a total sample number of 1305.

\section{Data collection procedures}

Their socio-demographic details were collected by the field workers through face-to-face interviews at their homes using structured questionnaires with the children and/or their parents/legal guardians. The ocular examination at the clinic consisted of visual acuity measurements, auto-refraction and subjective refraction, pen torch examination, direct ophthalmoscope observation and colour vision testing. The inclusion criterion for this study was school children (aged 7-17) who had a written consent from the parents or guardians. Children with any evidence of ocular pathology, trauma, previous ocular surgery, long-term use of medication and those born to parents who were born outside South Africa were excluded from the study. The pseudo-isochromatic colour plate test, Colour Vision Testing Made Easy (CVTME), was used to assess the colour vision of all the participants. All the testing was conducted under binocular viewing conditions in an optometry clinic with standard illumination, the details of the test process having been described previously [16].

\section{Data analysis}

Data were entered into excel spreadsheet and then exported to the Statistical Package for Social Sciences (SPSS version 24) for analysis. Descriptive statistics was used to present the participant's socio-demographic 
characteristics. Chi square $\left(\chi^{2}\right)$ test was used to establish the statistical significances, with p-values of less than 0.05 being considered statistically significant.

\section{Results}

A total of 1305 school children participated in the study, their ages ranging from 7-17 years, with a mean ( \pm standard deviation) of $12.06( \pm 1.8)$ years. There were 704 (53.9\%) females and 601 (46.1\%) males, while 719 children (55.1\%) were aged 7-12 years and 586 (44.9\%) were aged 13-17. The findings of CCVD among the 1305 subjects are shown in Table 1 . The prevalence of CCVD was $29(2.2 \%)$ (95\% CI 0.9-3.1), which was higher in males $(25,4.2 \%)$ (95\% CI 3.1-6.4) than females (4, 0.6\%) (95\% CI 0.1-1.1). There was a statistically significant difference in the prevalence of CCVD for boys $(p=0.00)$, but not for girls $(p=0.14)$. There were more $(19,1.5 \%)$ deutans than protans $(10,0.7 \%)$. Similarly, there were significantly more protans $(9,1.5 \%)$ and deutans (16, $2.7 \%$ ) in boys than girls, who had one (0.1) protan and three $(0.4 \%)$ deutans $(\mathrm{p}<0.05)$. No child was totally colour blind among the study population. The prevalence of CCVD was compared among younger and older children, although the difference between the age groups was not statistically significant $(\mathrm{p}=0.12)$.

\section{Discussion}

Irrespective of age, race and ethnicity, there is a general paucity of information on the colour vision status of South Africans. Colour vision assessments are important to enable those affected to follow adaptive strategies that could minimise the risks associated with the disorder. This, the first report on CCVD in healthy Black South Africans school children, provides a basic database on the prevalence of CCVD in the region and an opportunity to compare data with other race and ethnic groups from a number of countries.

Congenital red-green colour vision defects are the most common types of colour vision deficiencies [16]. Colour Vision Testing Made Easy (CVTME) is the

Table 1 Prevalence of CCVD according to age and gender

\begin{tabular}{llllll}
\hline Category & $\begin{array}{l}\text { Total } \\
\mathbf{n}(\%)\end{array}$ & $\begin{array}{l}\text { Protans } \\
\mathbf{n}(\%)\end{array}$ & $\begin{array}{l}\text { Deutans } \\
\mathbf{n}(\%)\end{array}$ & $\begin{array}{l}\text { CCVD } \\
\mathbf{n}(\%)[95 \% \mathbf{C l}]\end{array}$ & p-value \\
\hline $\begin{array}{llllll}\text { Age (years) } \\
7-12\end{array}$ & 719 & $7(1.0)$ & $6(0.8)$ & $13(1.8)[0.7-2.8]$ & 0.12 \\
$13-17$ & 586 & $3(0.5)$ & $13(2.2)$ & $16(2.7)[1.1-4.2]$ & \\
Gender & & & & & \\
Male & $601(46.1)$ & $9(1.5)$ & $16(2.7)$ & $25(4.2)[3.1-6.4]$ & 0.00 \\
Female & $704(53.9)$ & $1(0.1)$ & $3(0.4)$ & $4(0.5)[0.1-1.1]$ & \\
Total & 1305 & $10(0.7)$ & $19(1.5)$ & $29(2.2)[0.9-3.1]$ & \\
\hline
\end{tabular}

paediatric gold standard for identifying and classifying red-green colour vision defects in children as young as 3 years $[16,17]$, with a mean sensitivity of $91 \%$, a mean specificity of $100 \%$, in addition to having good retest reliability [17]. The distribution of CCVD was consistent across the age categories (7-12: $1.8 \%, 13-17$ : $2.7 \%)$, and although this shows an increase in the prevalence of the defect with increasing age, the difference was not statistically significant $(\mathrm{p}=0.12)$. As CCVD is a hereditary defect, the prevalence in different age groups is statistically insignificant $(p>0.05)$. Table 2 provides an overview of the prevalence of CCVD in selected studies among individuals of different ages, races and ethnicities compared with findings from this study.

Total congenital colour vision deficiency was not detected in this study, which confirms the view that the trait, which is autosomal, is rare [1]. The prevalence of CCVD in this study was $2.2 \%$, which is similar to the prevalence rates of $2.3 \%$ in Ibadan, South-West Nigeria [18], 2.6\% in Port-Harcourt, Southern Nigeria [19], $1.9 \%$ [2] and $2.1 \%$ [20] in Nepal, and slightly higher than $1.5 \%$ found in Zaria, Northern Nigeria [21] among school children. This finding is also comparable with that of Guntur City, Andhra Pradesh, which reported a prevalence rate of $1.9 \%$ [22]. However, the result of this study is lower than the prevalence rate of $4.1 \%$ and 4.2\% reported in Southern [23] and Central Ethiopia [24] respectively among school children. This finding is also lower than a study done in Manipur, India, which reported a prevalence rate of 5.8\% [5]. Differences in study population, geographical area, race, ethnicity and techniques used to assess colour vision could be some of the factors responsible for such variations (Table 2). Higher prevalence rates of CCVD have been reported among Asians and Caucasians compared to African populations [9]. For example, the prevalence of CCVD in Japan was $4 \%, 6.5 \%$ in China, $7.3 \%$ in Turkey, $4.7 \%$ in Iran and $2.8 \%$ to $8.2 \%$ in India [9].

The prevalence of CCVD was noted to be higher in males $(4.2 \%)$ than females $(0.5 \%)$, which is consistent with other studies $[25,26]$. This may be attributed to the fact that CCVD is usually inherited by an X-linked recessive pattern [9]. Therefore, the prevalence rate of CCVD is found to be higher in males as they have only one X-chromosome, and are prone to suffer from the defect while females are carriers [9]. Deutans occurred at a higher frequency than protans among both male and female red-green colour deficient children (Table 1). Similar frequency trends have been reported in earlier studies among different populations [24, 25]. 
Table 2 Characteristics of congenital colour vision defects (CCVD) reported compared with the findings of the current study

\begin{tabular}{|c|c|c|c|c|c|c|c|}
\hline \multirow[t]{2}{*}{ Study } & \multirow[t]{2}{*}{ Race } & \multirow[t]{2}{*}{ Instrument used } & \multirow{2}{*}{$\begin{array}{l}\text { Number } \\
\text { M/F }\end{array}$} & \multirow[t]{2}{*}{ Age } & \multirow[t]{2}{*}{ Overall prevalence (\%) } & \multicolumn{2}{|c|}{$\begin{array}{l}\text { Prevalence } \\
(95 \% \mathrm{CI})\end{array}$} \\
\hline & & & & & & $\bar{M}$ & $F$ \\
\hline \multicolumn{8}{|l|}{ Africa } \\
\hline This study & Zulu & CVTME & $704 / 601$ & $7-17$ & 2.2 & 4.2 & 0.6 \\
\hline Ugalahi et al. [18] & Nigerian & Ishihara, FM D-15 & $769 / 866$ & $13.9 \pm 1.9$ & 2.3 & 3.8 & 0.9 \\
\hline Tabansi et al. [19] & Nigerian & Ishihara & $N / R$ & $N / R$ & 2.6 & $N / R$ & $N / R$ \\
\hline Abah et al. [21] & Nigerian & Ishihara & $149 / 178$ & $5-17$ & 1.5 & $N / R$ & $N / R$ \\
\hline Woldeamanuel and Geta [23] & Ethiopian & Ishihara & 844 & $7-18(11.75 \pm 2.5)$ & 4.1 & 3.6 & 0.6 \\
\hline Mulusew and Yilikal [24] & Ethiopian & Ishihara & 1040 & $12 \pm 2.43$ & $4.2(95 \%$ Cl 2.98-5.42) & $N / R$ & $N / R$ \\
\hline \multicolumn{8}{|l|}{ Asia/Middle East } \\
\hline Ahsana et al. [5] & Iranian & Ishihara & $1352 / 1302$ & $N / R$ & $N / R$ & 8.73 & 1.69 \\
\hline Reddy et al. [22] & Indian & Ishihara & $841 / 788$ & $10-15$ & 1.9 & 1.71 & 0.814 \\
\hline Rajavi et al. [26] & Iranian & Ishihara & $1069 / 1081$ & 7-12 (mean, 9.4 \pm 1.7$)$ & $2.2 \%(95 \% \mathrm{Cl} 1.5-3)$ & 3.5 & 1 \\
\hline Niroula and Saha [2] & Chhetri & Ishihara & $474 / 490$ & $10-19$ & $N / R$ & 3.8 & 0 \\
\hline Shrestha et al. [20] & Chhetri & Ishihara & $1050 / 951$ & $\begin{array}{l}10.35 \pm 2.75 \mathrm{M} \\
10.54 \pm 2.72 \mathrm{~F}\end{array}$ & 2.1 & 3.9 & 0 \\
\hline Napaporn et al. [27] & Thai & Ishihara & 3056 & $6-7$ & 4.2 & 3.7 & 0.5 \\
\hline \multicolumn{8}{|l|}{ Europe } \\
\hline Gallo et al. [28] & Italian & Ishihara & 63933 & $11-14$ & 4.8 & & \\
\hline Azizoğlu et al. [29] & Turkish & Ishihara & 823 & $4-10$ & 3.8 & & \\
\hline Rose et al. [30] & Caucasian & Ishihara & 131 & $5-18$ & 5.3 & & \\
\hline Birch and Platts [31] & Caucasian & Ishihara & $258 / 255$ & $3-11$ & $N / R$ & 6.6 & 0.4 \\
\hline
\end{tabular}

$M$ male, $F$ female, $\mathrm{Cl}$ confidence interval, $N / R$ not reported

\section{Conclusion}

The prevalence of CCVD among Black school children in Durban was $2.2 \%$, which is comparable to those previously reported in Southwest and South Nigeria, but lower than those in Central and South Ethiopia. These results strengthen the need for local studies to establish complete databases in the African continent. The level of awareness of CCVD can be enhanced by conducting routine colour vision screenings at schools, which will help the affected individuals to recognise their limitation and orientate their choice of future careers.

\section{Limitations}

This study screened only for red-green CCVD as the CVTME is not able to detect blue-yellow deficiency. Children who were diagnosed with CCVD were not retested using another colour vision test with more sensitivity to validate the results. It is recommended that further studies be done to determine the magnitude and severity of CCVD using an anomaloscope. The results of the study are based on 1305 Black school children of isiZulu ethnicity from Durban and might not provide for a complete analysis of Black children across South Africa.
It is recommended that other children of South African race and ethnic groups be studied so that comparative inferences can be made.

\section{Additional file}

Additional file 1. Map showing the South, Inner West and Outer West regions of Durban. (https://www.google.com/ search?q=South, +Inner+West+and+Outer+West+regio ns+of+Durban\&safe $=$ strict\&rlz=1C1CHBD_enZA821ZA821\&sourc $\mathrm{e}=$ Inms\&tbm $=$ isch\&sa $=$ X\&ved $=0$ ahUKEwjpq IXQpcTiAhXWSXUIHbRBD z8Q_AUIECgD\&biw=1280\&bih=610).

Abbreviations

CCVD: congenital colour vision deficiency; CVTME: Colour Vision Testing Made Easy.

\section{Acknowledgements}

KPM and DBS are University of KwaZulu-Natal (UKZN) Developing Research Innovation, Localisation and Leadership in South Africa (DRILL) fellows. DRILL, is a NIH D43 grant (D43TW010131) awarded to UKZN in 2015 to support a research training and induction programme for early career academics. The content is solely the responsibility of the authors and does not necessarily represent the official views of DRILL and the National Institutes of Health. The authors would like to thank the city councillors, traditional leaders, school administrators, data collectors and other key community figures for their 
cooperation. The authors would also like to thank Ms. Carrin Martin for reviewing this article and providing valuable comments.

\section{Authors' contributions}

KPM: conception and initiation of the study, develop proposal, implement the study, analysed it and wrote the manuscript. DBS: conception, developed the proposal and wrote the draft manuscript. Both authors read and approved the final manuscript.

\section{Funding}

Not applicable. There was no sources of funding for this study.

\section{Availability of data and materials}

Not applicable. All the data is in the result.

\section{Ethics approval and consent to participate}

Ethical approval for undertaking the study was obtained from the Biomedical Research Ethics Committee (BREC) of the University of KwaZulu-Natal, Durban, South Africa (Ethical clearance reference number BE311/12). Permission was obtained from the Dean, School of Health Sciences at the University of KwaZulu-Natal to conduct the research at the University's Optometry clinic. Permission was also sought from community leaders and school administrators of the areas where the participants were recruited from. All the participants were given a copy of the information document which explained the purpose and procedures of the study. The inclusion criterion for this study was school children (aged 7-17) who had a written consent from the parents or guardians. Child assents were obtained from the participants as the participant were children under the age of 18 years. Participants requiring further investigations were referred to an ophthalmologist for further assessment and management. The study was conducted in accordance with the tenets of the Declaration of Helsinki for research involving human subjects. For confidentiality, the participants' names and details were not used outside the study. Colour deficient students and their parents received necessary advice about the problem, its prognosis and implication on future career choices.

\section{Consent for publication}

Not applicable.

\section{Competing interests}

The authors declare that they have no competing interests.

Received: 25 January 2019 Accepted: 7 June 2019

Published online: 10 June 2019

\section{References}

1. Neitz J, Neitz M. The genetics of normal and defective colour vision. Vis Res. 2011;51(7):633-51.

2. Niroula DR, Saha CG. The incidence of colour blindness among some school children of Pokhara, Western Nepal. Nepal Med Coll J. 2010;12(1):48-50.

3. Dohvoma VA, Mvogo SR, Kagmeni G, Emini NR, Epee E, Mvogo CE. Colour vision deficiency among biomedical students: a cross-sectional study. Clin Ophthalmol. 2018;12:1121-4.

4. Chan XBV, Goh SMS, Tan NC. Subjects with colour vision deficiency in the community: what do primary care physicians need to know? Asia Pac Fam Med. 2014;13:10.

5. Ahsana SH, Hussain R, Fareed M, Afzal M. Prevalence of red-green colour vision defects among muslim males and females of Manipur, India. Iran J Public Health. 2013;42(1):16-24.

6. Cruz EM, Cerdana HG, Cabrera AM, Garcia CB, Santos-Morabe ET, Nanagas M, Lourdes R. Prevalence of colour-vision deficiency among male high school students. Philipp J Ophthalmol. 2010;35(1):20-4.

7. Simunovic MP. Colour vision deficiency. Eye. 2010;24(5):747-55.

8. Khalaj M, Barikani A, Mohammadi M. Prevalence of colour vision deficiency in Qazvin. Zahedan J Res Med Sci. 2014;16(1):91-3.

9. Birch J. Worldwide prevalence of red-green colour deficiency. J Opt Soc Am A Opt Image Sci Vis. 2012;29(3):313-20.
10. Chakrabarti A, Chakraborti S. Red-green colour vision deficiency and lack of awareness among rural school students in India. Iran J Public Health. 2015:44(7):1018-20.

11. Cole BL. The handicap of abnormal colour vision. Clin Exp Optom. 2004:87(4-5):258-75.

12. Birch J. Diagnosis of defective colour vision: colour vision deficiency. Oxford: Butterworth-Heinemann, Health Promotion Board; 2001.

13. Cole BL. Assessment of inherited colour vision defects in clinical practice. Clin Exp Optom. 2007:90(3):157-75.

14. Rigaudiere F, Leid J, Vienot F, Le Gargasson JF. Neurophysiological basis and clinical tests for assessment of $X$-linked colour vision deficiencies in school children. J Fr Ophtalmol. 2006;29(1):87-102.

15. Kirkwood BR, Sterne JA. Essentials of medical statistics. 2nd ed. Cambridge: Blackwell Science Limited; 2003. p. 420.

16. Cotter SA, Lee DY, French AL. Evaluation of a new colour vision test: "colour vision testing made easy". Optom Vis Sci. 1999;76:631-6.

17. Barnhardt C, Block SS, Deemer B, Calder AJ, DeLand P. Colour vision screening for individuals with intellectual disabilities: a comparison between the Neitz Test of colour vision and Colour Vision Test Made Easy. Optometry. 2006;77:211-6.

18. Ugalahi MO, Fasina O, Ogun OA, Ajayi BG. Prevalence of congenital colour vision deficiency among secondary school students in Ibadan, SouthWest Nigeria. Niger Postgrad Med J. 2016;23(1):93-6.

19. Tabansi PN, Anochie IC, Nkanginieme KE, Pedro-Egbe CN. Screening for congenital colour vision deficiency in primary children in Port Harcourt city; teachers' knowledge and performance. Niger J Med. 2008;1 7:428-32.

20. Shrestha RK, Joshi MR, Shakya S, Ghising R. Colour vision defects in schoo going children. J Nepal Med Assoc. 2010;50(180):264-6.

21. Abah ER, Oladigbolu KK, Samaila E, Gani Ikilama A. Ocular disorders in children in Zaria children's school. Niger J Clin Pract. 2011;14:473-6.

22. Reddy AVP, Prasad GRBKV. Prevalence of colour blindness in school children in Guntur City, Andhra Pradesh. Int J Contemp Med Res. 2017;4(11):2266-8.

23. Woldeamanuel GG, Geta TG. Prevalence of colour vision deficiency among school children in Wolkite, Southern Ethiopia. BMC Res Notes. 2018;11:838. https://doi.org/10.1186/s13104-018-3943-z.

24. Mulusew A, Yilikal A. Prevalence of congenital colour vision defects among school children in five schools of Abeshge District, Central Ethiopia. JOECSA. 2013;17(1):10-4.

25. Fareed M, Anwar MA, Afzal M. Prevalence and gene frequency of colour vision impairments among children of six populations from North Indian region. Genes Dis. 2015;2(2):211-8.

26. Rajavi Z, Sabbaghi H, Baghini AS, Yaseri M, Sheibani K, Norouzi G. Prevalence of colour vision deficiency and its correlation with amblyopia and refractive errors among primary school children. J Ophthalmic Vis Res. 2015;10:130-8

27. Napaporn T, Manassakorn A, Worapong A, Kupat J, Chuwuttayakorn J, Wattananikorn S. Vision screening in schoolchildren: two years results. J Med Assoc Thai. 2004;87(6):679-84.

28. Gallo PG, Panzo M, Lantieri PB, Risso D, Conforti G, Lagonia P, et al. Some psychological aspects of colour blindness at school: a field study in Calabria and Basilicata (southern Italy). Color Res Appl. 2003;28:216-20.

29. Azizoğlu S, Crewther SG, Serefhan F, Barutchu A, Göker S, Junghans BM. Evidence for the need for vision screening of school children in Turkey. BMC Ophthalmol. 2017;17:230. https://doi.org/10.1186/s1288 6-017-0618-9.

30. Rose K, Younan C, Morgan I, Mitchell P. Prevalence of undetected ocular conditions in a pilot sample of school children. Clin Exp Ophthalmol. 2003;31:237-40.

31. Birch J, Platts CE. Colour vision screening in children: an evaluation of three pseudoisochromatic tests. Ophthal Physiol Opt. 1993;14:344-9.

\section{Publisher's Note}

Springer Nature remains neutral with regard to jurisdictional claims in published maps and institutional affiliations. 